\title{
LXIX. On a new method of reducing lunar observations for the determination of the longitude
}

\section{Charles Rumker Esq. F.R.A.S.}

To cite this article: Charles Rumker Esq. F.R.A.S. (1836) LXIX. On a new method of reducing lunar observations for the determination of the longitude , Philosophical Magazine Series 3 , 8:48, 373-383, DOI: $10.1080 / 14786443608648892$

To link to this article: http://dx.doi.org/10.1080/14786443608648892

曲 Published online: 01 Jun 2009.

Submit your article to this journal $[\pi$

Џll Article views: 3

Q View related articles $\sqsubset$ 
GENUS AND SPECIES.

New genus allied to Scopelus ...

E Placoid fish not yet named.... (Coal Shale.) North Stafford.

E Placoid fish not yet named.... (Coal Shale.) North Stafford.

E Placoid fish not yet named.... (Coal Shale.) North Stafford.

E Placoid fish not yet named.... (Coal Shale.) North Stafford.

Scomberoid not yet named ... (London Clay.) Sheppey.

c Ten species not yet named.... (London Clay.) Sheppey.

c New genus not yet named.... (Tertiary Beds.) CEningen.

LXIX. On a new Method of reducing Lunar Observations for the Determination of the Longitude. By Charles Rumkei, Esq., F.R.A.S.*

To Lieut.-General Sir Thomas Macdougall Brisbane, K.C.B., Sir, Pres. R.S. E., F.R.S.L., F. Ast.S., \&c.

THE lively interest which you took in the determination of the longitude by lunars, and the success which attended your observations, animate me to submit the following method, admitting of greater accuracy when either altitude is low, to your approval and patronage. Allow me to remind you here, that already when $I$ had the honour of accompanying you on your passage to Australia, I had occasion to allude to the necessity of a more strict method, suitable to the circumstances. This subject has since been treated by a celebrated astronomer. His method appears to me, however, not likely to be generally adopted by seamen, and requires, moreover, a particular ephemeris, which becomes useless on ordinary occasions, when the usual methods answer every purpose.

I hope, therefore, that the following method, which requires no other tables than the Nautical Almanac, and may, according to circumstances, be computed with more or less precision, will meet your approbation.

The object of the present lines is to correct the error committed in the usual methods of clearing the apparent distance between sun and moon by taking out the refraction for the central altitude of both bodies, whereas it is the refraction for those points of their limbs, the distance of which is actually measured, that should be used in the calculation.

As introduction, it may not be useless to remark, that the usual methods of clearing the distance, supposing the altitudes known from observation, can be classed into direct and approximative ones. For thus, as all the former methods are derived from the equation existing between the sides of

* Communicated by Sir Thomas M. Brisbane, K.C.B., \&c. A portion of this paper was inserted in our Number for October last : this having required some corrections, we now give the Communication entire. 
the two triangles formed by the apparent zenith distances and distance, and the true zenith distances and distance, and only differ by slight variations in the manner of finding thence the true distance, or side of the latter triangle opposite to the angle at the zenith common to both triangles, the latter methods unite all in computing in the apparent triangle the angle at the sun and moon, and the sides adjacent thereto in two rightangled triangles having for hypothenuses the corrections of the sun's and moon's altitudes. These sides are the corresponding corrections of the distance.

Let $\mathbf{D}$ designate the apparent distance of the centres, $S$ and $M$ the above angles at the sun and moon, $\rho-\pi$ the difference between parallax and refraction or correction of altitude, then is the true distance of centres $=\mathrm{D}+\operatorname{cosine} \mathrm{S} .(\rho-\pi)$ + cosine $M\left(\rho^{\prime}-\pi^{\prime}\right)+\alpha\left(\rho-\pi^{\prime}\right)^{2}+\beta\left(\rho^{\prime}-\pi^{\prime}\right)^{2}++$.

The moon's parallax being greater than her refraction, the second correction becomes negative; and when one of the angles is obtuse, its cosine takes the opposite sign. The fundamental formula of all approximative methods is,

$$
\begin{aligned}
& \text { true distance }=\mathrm{D}+\left(\frac{\sin h-\sin \mathrm{H} \cos \mathrm{D}}{\cos \mathrm{H} \sin \mathrm{D}}\right)(\rho-\pi) \\
& +\left(\frac{\sin \mathrm{H}-\sin h \cos \mathrm{D}}{\cos h \sin \mathrm{D}}\right)\left(\rho^{\prime}-\pi^{\prime}\right)+++, \ldots
\end{aligned}
$$

where $\rho$ and $\pi$ refer to that altitude $h$ or $\mathrm{H}$ which stands first and by itself in the parenthesis. Lyons obtains by executing the division,

$$
\begin{aligned}
& \mathrm{D}+(\sin h \sec \mathrm{H} \operatorname{cosec} \mathrm{D}-\tan \mathrm{H} \cot \mathrm{D})(\rho-\pi) \\
& +(\sin H \sec h \operatorname{cosec} \mathrm{D}-\tan h \cot \mathrm{D})(\rho-\pi)++ \text {. } \\
& \text { If we make }\left(\frac{\sin h-\sin H \cos D}{\cos H \sin D}\right)(5-\pi) \\
& =\left(1-1+\frac{\sin h-\sin H \cos \mathrm{D}}{\cos \mathrm{H} \sin \mathrm{D}}\right)(\rho-\pi) \\
& =\left(1-\frac{2 \cos \frac{1}{2}(\mathrm{D}+\mathrm{H}+h) \sin \frac{1}{2}(\mathrm{D}+\mathrm{H}-h)}{\cos \mathrm{H} \cdot \sin \mathrm{D}}\right)(\rho-\pi),
\end{aligned}
$$

we obtain the one part of Mendoza Rios' approximative formula to which the other is analogous; and by separating in Lyons's method the moon's parallax from the refraction, thence results the correction of the distance for the moon's parallax only $=$ hor. par. $\times\left[\frac{\sin \varangle \text { alt. }}{\tan \bar{D}}-\frac{\sin \odot \text { alt. }}{\sin \bar{D}^{-}}\right]$, which is identical in Elford's, Thomson's, and Lynn's tables, is found graphically by Kelly, and by Norie in his linear tables, and which Thomson finds with his lunar scale; and it is only in 
the manner of allowing for the refraction and the sun's parallax that the above authors differ; all of whom, however, with the exception of Lymn, have erred in using in the calculation the apparent altitude, whereas the apparent altitude corrected for refraction should have been used. On the same grounds the usual tables exhibiting the moon's correction by inspection, including parallax and refraction, are erroneously computed.

By approximative methods are not to be understood methods that admit of less accuracy, but such as approach the truth by a series of which the last terms vanish, or, which answers the same purpose, by a gradual substitution in the calculation of terms found by a former approximation. The approximative methods have, particularly to seamen, that advantage above the direct ones, that the trigonometrical calculation need only be executed to the nearest minute; and as the correction of the distance never can exceed that of the altitude, and as its sign, as well as amount, can nearly be estimated from the position which the observed bodies occupy, essential errors may easily be avoided; moreover, they offer an easy means of reducing the refraction to the points of the limbs brought into contact when observing their distance, as shall be shown in what follows: To deduce from the observed altitude of the upper or lower limb the apparent altitude of the centre, the horizontal semidiameter must be diminished for refraction by a correction to be taken out from the table at the end of this paper: in order to find the vertical diameter, the moon's semidiameter. requires moreover the usual augmentation on account of parallax. From another table, too extensive for our limits here, the reduction from the apparent to the true zenith must be taken, which may also be computed after the following formula:

$$
\frac{\sin \phi \sin h-\sin \delta}{\cos h} \times \frac{2 \sin \phi}{\frac{a^{2}+b^{2}}{a^{2}-b^{2}}}+\cos 2 \phi=\text { tang. reduction, }
$$

neglecting higher powers of $a^{8}-b^{2}$. This reduction assuming the ratio of axes $\frac{302 \cdot 8}{303 \cdot 8}$ is very nearly $=1360^{\prime \prime} \cdot \frac{\sin \phi}{\cos h}$ $(\sin \varphi \sin h-\sin \delta$ ), where $h$ denotes the true altitude, $\phi$ the latitude, $\delta$ the declination, attention being had to its sign. Tables for the correction of the horizontal parallax on account of the spheroidical figure of the earth are contained in several nautical works, or supplied by a simple calculation. Let us designate by,

$\mathrm{D}$, the apparent distance of centres;

$d$, the distance of the points of contact or observed distance of limbs; 
$H$, the greater, $h$ the less, apparent altitude of centres;

$\mathbf{H}^{\prime}$, the greater, $h^{\prime}$ the less, apparent altitude of the points of contact;

$r$, the semidiameter parallel to the horizon (augmented if the moon's) of the upper body;

$\rho-\pi$, the correction of the upper altitude;

$\rho^{\prime}-\pi^{\prime}$, the correction of the lower altitude;

$\theta$, the true distance of the limbs, to which the equatorial horizontal semidiameters must be added to obtain the true distance of the centres.

Let $A$ be the distance of the middle of the apparent distance of the centres, and $A^{\prime}$ the distance of the middle of the apparent distance of the limbs from the highest point in the apparent distance or its prolongation, that is, from that point in a great circle drawn through sun and moon where the effect of parallax and refraction is 0 ,- then is

$\tan \mathbf{A}=\frac{\tan \frac{1}{2}(\mathrm{H}-h)}{\tan \frac{1}{2}(\mathrm{H}+h) \tan \frac{1}{2} \mathrm{D}}$ and $\mathrm{A}^{\prime}=\frac{1}{2} d+r+\mathbf{A}-\frac{1}{2} \mathrm{D}$

whence we obtain the apparent altitudes of the points of contact,

$\sin \mathrm{H}^{\prime}=\frac{\cos \left(\frac{1}{2} d-\mathrm{A}^{\prime}\right) \sin \mathrm{H}}{\cos \left(\frac{1}{2} \mathrm{D}-\mathrm{A}\right)}$ and $\sin h^{\prime}=\frac{\cos \left(\frac{1}{2} d+\mathrm{A}^{\prime}\right) \cos h}{\cos \left(\frac{1}{2} \mathrm{D}+\mathrm{A}\right)}$

which are also found by $\mathrm{H}^{\prime}-\mathrm{H}=r \tan \mathrm{H} \tan \left(\frac{1}{2} \mathrm{D}-\mathrm{A}\right)$ and $h^{\prime}-h=r^{\prime} \tan h \tan \left(\frac{1}{2} \mathrm{D}+\mathrm{A}\right)$ and adding $\mathrm{H}^{\prime}-\mathrm{H}$ and $h^{\prime}-h$ to the apparent altitudes of the centres above the sensibje horizon and subtracting from the sum the change of refraction from $\mathrm{H}^{\prime}$ to $\mathrm{H}$ and $h^{\prime}$ to $h$. But if $\mathrm{A}>\frac{1}{2} \mathrm{D}, \mathrm{H}^{\prime}-\mathrm{H}$ is to be subtracted from the greater altitude, and the change of declination to be added thereto; the same method is to be followed when the distance of the moon's remote limb from a star is observed. It being, however, not so much an error in the altitude as an error in the refraction that materially affects the calculation, and this refraction not being sensibly altered by a few seconds of difference of altitude, the change of refraction may safely be neglected. For the apparent altitudes of the points of contact of the sun and moon above the horizon, compute strictly the refractions $g$ and $g^{\prime}$ with regard to barometer and thermometer, and add the sum of these refractions to the observed distance of the limbs. From the same apparent altitudes of the points of contact above the sensible horizon, find, by applying thereto the above-stated reduction, the altitudes $\mathrm{H}^{\prime}$ and $h^{\prime}$ with respect to the true zenith, and deduct from each the corresponding refraction found before, and compute for the rest the parallaxes in altitude $\pi$ and $\pi^{\prime}$, and 
subtract their sum $\pi+\pi^{\prime}$ from the observed distance augmented by the refractions, and call the remainder $d+\rho+\xi^{\prime}-\pi-\pi^{\prime}$ $=\delta$.

Find also for each altitude the corrections $\varrho-\pi$ and $\xi^{\prime}-\pi^{\prime}$; then is

$$
\begin{aligned}
& \theta=\delta-\frac{\cos \left(\mathbf{H}^{\prime}+\frac{1}{2} d-\mathbf{A}^{\prime}\right) \cdot(\rho-\pi)}{\cos \mathbf{H}^{\prime} \cos \left(\frac{1}{2} d-\mathbf{A}^{\prime}\right)}-\frac{\cos \left(h^{\prime}+\frac{1}{2} d+\mathbf{A}^{\prime}\right) \cdot\left(\rho^{\prime}-\pi^{\prime}\right)}{\cos h^{\prime} \cos \left(\frac{1}{2} d+A\right)} \\
& +\frac{\cos \left(\mathbf{H}^{\prime}+\frac{1}{2} d-\mathbf{A}^{\prime}\right) \cos \left[\mathbf{H}^{\prime}-\left(\frac{1}{2} d-\mathbf{A}^{\prime}\right)\right](\rho-\pi)^{2} \cdot \sin 1^{\prime \prime}}{2 \tan d \cos ^{2} \mathbf{H}^{\prime} \cos ^{2}\left(\frac{1}{2} d-\mathbf{A}^{\prime}\right)} \\
& +\frac{\cos \left(h^{\prime}+\frac{1}{2} d+\mathbf{A}\right) \cos \left[h^{\prime}-\left(\frac{1}{2} d+\mathbf{A}^{\prime}\right)\right]\left(\rho^{\prime}-\pi^{\prime}\right)^{2} \cdot \sin 1^{\prime \prime}}{2 \tan d \cos ^{2} h^{\prime} \cos ^{2}\left(\frac{1}{2} d-\mathbf{A}^{\prime}\right)}-++
\end{aligned}
$$

If we call the first correction $\alpha$, the second $\beta$, then is:

$$
\theta=\delta-\alpha-\beta+\left[\left(\rho-\pi-\frac{1}{2} \alpha\right) \alpha+\left(\rho^{\prime}-\pi^{\prime}-\frac{1}{2} \beta\right) \beta\right] \frac{\sin 1^{\prime \prime}}{\tan (\delta-\alpha-\beta)}
$$

to which both horizontal semidiameters are to be added to find the true distance of the centres. The square of the sun's correction can always be neglected, and that even of the moon's correction disappears when $d$ is near $90^{\circ}$, or when the moon's correction is small. All four corrections disappear when the distance is the supplement of the sum of the altitudes; but when the distance is equal to the difference of the altitudes, all other corrections vanish except the first one, which becomes $=2(p-\pi)$.

The first two corrections only, however, need be computed, as the others can be taken as a small third correction from a table contained in most nautical works, reith its sign, which becomes negative when $\delta>90$; so that this method has the advantage that no difference of cases need be attended to, as in that of Witchell's, whose example $I$ have followed in the computation of it. For if we call, of the two first corrections, the one proceeding from the sun $\mathrm{S}$ and that from the moon $\mathrm{M}$, then is,

$$
\theta=\delta-\mathrm{S}+\mathrm{M} \pm \text { third correction, }
$$

which latter one, in the absence of the tables, may be found by the formula ( $\mathbb{C} ' s$ corr. $-\frac{1}{2} M$ ). $M \cot \theta \sin 1^{\prime \prime}$.

To the semidiameters, which are to be added to the observed distance to obtain the apparent distance of the centres, a correction should be applied on account of inclination to the horizon, for which Mendoza Rios has given a table. This inclination to the horizon is found by sin. inclination = $\sin \mathrm{H} \sec \left(\frac{1}{2} \mathrm{D}-\mathrm{A}\right)$. In the subsequent example this inclination is $=90^{\circ}$; so that the vertical semidiameters have been used. As however the distance of the centres enters only into Third Series. Vol. 8. No. 48. May 1836. 
the approximative calculation, the correction for inclination may be omitted in this method.

To illustrate this method we shall choose the example given by Professor Schumacher in his Ephemeris for 1835, which from 21 feet elevation above the level of the sea would become the following:

1st Example. June 18, 1835 , in $23^{\circ} 57^{\prime} \mathrm{N}$. latitude, and $172^{\circ} 22^{\prime} \mathrm{E}$. longitude, the following observations were made. Therm. 90 Fahr.; barom. 28.6 Engl.

$\odot$ Lower Limb. 835535

Dip $\frac{-421}{8351 \quad 14}$

$\odot$ 's semid. +1545

App. alt. $\overline{84 \quad 659}$

Red. to true zen. $+\quad 35$
\& Upper Limb. $515 \mathbf{5 0}$

…............. $\frac{-421}{51129}$

(c's hor. semid. 154

Refraction -20$\}-1445$ vert.semid.

Parallax $+1$

Ap. alt. above hor. 45644

Reduct. to true zen. +123

$h=458 \quad 7$

Observed Distance of Limbs.

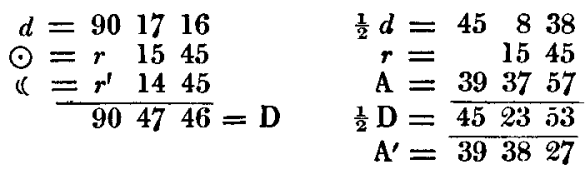

semid. $\odot=r \quad 1545$

semid. " $\equiv r^{\prime} \quad 1445$

Calculation.

$$
\begin{aligned}
& \text { H } 84 \quad 734 \\
& \begin{array}{llll}
h & 4 & 58 & 7
\end{array}
\end{aligned}
$$

$$
\begin{array}{ccccc}
\frac{1}{2}(\mathrm{H}+h) & 44 & 32 & 50 \\
\frac{1}{2}(\mathrm{H}-h) & \mathbf{3 9} & \mathbf{3 4} & \mathbf{4 3} \\
\frac{1}{2} \mathrm{D} & \mathbf{4 5} & \mathbf{2 3} & \mathbf{5 3} \\
\hline \mathrm{A} & \mathbf{3 9} & \mathbf{3 7} & \mathbf{5 7}
\end{array}
$$

$$
\begin{array}{rlr}
\overline{842256} & \text { par. } \pi=1 \\
\pi-\rho & =\quad+\frac{4642}{\mathrm{~A}-\mathrm{R}} \\
\mathrm{P}+\pi-\varsigma-\mathrm{R} & =9638 \\
d & =901716
\end{array}
$$$$
\tan 9.0042
$$$$
\tan 0.9877
$$$$
\log 2.9754
$$$$
\frac{1}{2} \mathrm{D}+\mathrm{A} 85 \quad 750
$$$$
\begin{array}{llll}
h & 4 & 58 & 7
\end{array}
$$$$
\begin{array}{lll}
r^{\prime} & 15 & 5
\end{array}
$$$$
h-h \quad 155
$$$$
\text { App. alt. } 45644
$$$$
\text { refr. } \varrho=5^{\prime \prime}
$$$$
\begin{aligned}
& 51149 \\
& \hline
\end{aligned}
$$$$
\text { Change refr. for } h^{\prime}-h=20
$$$$
\begin{array}{lll}
5 & 11 & 29
\end{array}
$$

Red.zen. 123

refr. $R=8^{\prime} 19^{\prime \prime}$

$\tan 1.0607$

$\tan 8.9392$

$\log 2 \cdot 9567$

$\log 2 \cdot 9567$$$
51252
$$

Ref. 819

$$
\begin{aligned}
5433 & \text { par. } \mathrm{P}=\underline{551} \\
\mathrm{P}-\mathrm{R} & =+4642
\end{aligned}
$$




$$
\begin{aligned}
& \frac{1}{2} d 45 \quad 8 \quad 38 \\
& \begin{array}{llll}
\mathbf{A}^{\prime} & 39 & 38 & 27
\end{array}
\end{aligned}
$$

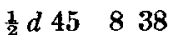

$$
\begin{aligned}
& \begin{array}{llll}
\mathrm{A}^{\prime} & 39 & 38 & 27
\end{array}
\end{aligned}
$$

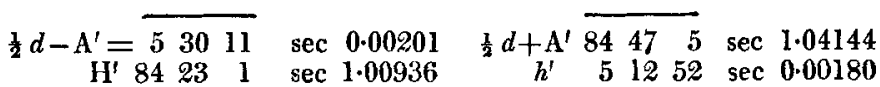

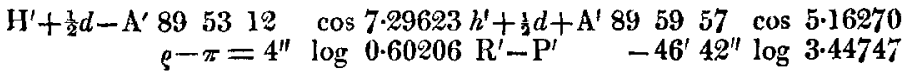

$$
\begin{aligned}
& \mathrm{S}=-0^{\prime \prime .08} \overline{\log 8.90966} \mathrm{M}=+0^{\prime \prime .45} \quad \overline{\log 9 \cdot 65341} \\
& \mathrm{M}=\quad+0.45 \\
& \delta=893038 \cdot 00 \\
& \theta=893038 \cdot 37 \\
& r=\quad 1545 \\
& r^{\prime}=\quad 154
\end{aligned}
$$

True cent. dist. $90 \quad 1127 \cdot 4 \quad 0^{\circ} 1^{\prime} 24^{\prime \prime} \cdot 6$ pr. $\log .2 \cdot 1065$

From Nautical Alm. prop. log. for midnigh $\quad 0.3250$

Mean time at Greenwich $12 \quad 258.5 \quad$ pr. $\log \overline{1 \cdot 7815}$

Mean time on board 23345200

$$
\text { Longitude } 1131 \quad 53.5 \text { East. }
$$

2nd Example. October 16,1835 , in $53^{\circ} 33^{\prime} \mathrm{N}$. latitude, and $9^{\circ} 58^{\prime}$ E. longitude, at 10 A.M. mean time, the following altitudes of the sun's and moon's lower limb and distance of their limbs were observed. Elevation of the eye 20 feet. Barom. 30.2; therm. 40 .

$$
\text { Dip } \begin{array}{r}
23 \stackrel{\odot}{4131} \\
-\quad 4 \quad 15 \\
\hline 234716
\end{array}
$$

$\left.\begin{array}{cr}\text { semid. } 16 & 4 \cdot 6 \\ \text { Dim. for refr. } & 2 \cdot 0\end{array}\right\}+16 \quad 2 \cdot 6$

$$
\begin{array}{r}
\overline{235318 \cdot 6} \\
+931 \cdot 0 \\
\hline 24 \quad 249 \cdot 6
\end{array}
$$$$
\operatorname{dip} \begin{array}{rr}
\begin{array}{l}
D \\
-30
\end{array} & 0 \\
-4 & 15 \\
\hline 452545
\end{array}
$$$$
\text { (c's hor. sem.15 18.7? }
$$$$
\text { aug. for par. } 10.5>15 \text { 28.8 }
$$$$
\text { dim. for ref. } 0.4\}
$$

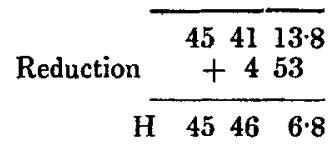

Distance.

$$
\begin{aligned}
& d=7241 \quad 13 \quad \frac{1}{2} d=362036.5 \\
& 1529 \cdot 2 \quad r=1529 \cdot 2 \\
& 16 \quad 4.6 \quad \mathrm{~A}=201838.0 \\
& D=\overline{731246 \cdot 8} \quad \overline{565444 \cdot 0} \\
& \begin{array}{lllll}
\frac{1}{2} \mathrm{D} & 36 & 36 & \mathbf{2 3} \cdot 0
\end{array} \\
& \mathrm{~A}^{\prime}=201821 \cdot 0
\end{aligned}
$$


$\mathrm{H}=4546 \quad 7$

$h=24$ \& 50

$\begin{array}{llllllll}\mathrm{H}+h=69 & 38 & 57 & \frac{1}{2}(\mathrm{H}+h) & 34 & 54 & 28 & \cot 0.1562619 \\ \mathrm{H}-h=21 & 43 & 16 & \frac{1}{2}(\mathrm{H}-h) & 10 & 51 & 38 & \tan 9.2829749\end{array}$

$\begin{array}{llllll}\frac{1}{2}(\mathrm{H}-h) & 10 & 51 & 38 & \tan 9 \cdot 2829749 \\ \frac{1}{2} \mathrm{D} & 36 & 36 & 23 & \cot 0 \cdot 1291056\end{array}$

A $2018 \quad 38 \quad \tan \overline{9.5683424}$

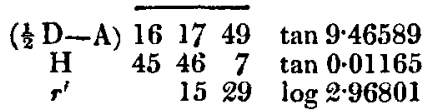

$\mathrm{H}^{\prime}-\mathrm{H} \quad 4^{\prime} 39^{\prime \prime} \log 2 \cdot 44556$

$\begin{array}{lll}45 & 41 & 14\end{array}$

454553 refr. $\theta^{\prime} 58^{\prime \prime} \cdot 1$

Reduction +453

$\mathrm{H}^{\prime}=\overline{455046}$

Refraction

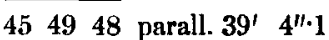

$$
\begin{aligned}
& \varepsilon-\pi=-\overline{38}^{\prime} 6^{\prime \prime} \cdot 0 \\
& \rho^{\prime}-\pi^{\prime}=+25 \cdot 5
\end{aligned}
$$

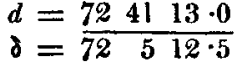$$
e-\pi+e^{\prime}-\pi^{\prime}=-\overline{360 \cdot 5}
$$

$\left(\frac{1}{2} D+A\right) \underset{24}{56} \quad \begin{array}{rrr}250 & 1 & \tan 0 \cdot 18611 \\ r & \tan 9 \cdot 64954\end{array}$

16 ह $\log 2.95453$

$h^{\prime}-h \quad 11^{\prime} 1^{\prime \prime} \quad \log 2 \cdot 82018$ $23 \quad 53 \quad 19$

24420 ref. cor. $2^{\prime} 13^{\prime \prime} \cdot 2$ $+931$

$h^{\prime} \quad 241351$ parallax $7 \cdot 7$

$$
\rho^{\prime}-\pi^{\prime \prime} \overline{25 \cdot 5}
$$

$$
\begin{aligned}
& \frac{1}{2} d=362036 \\
& \mathrm{~A}^{\prime}=2018 \quad 21 \\
& \left(\frac{x}{2} d-A^{\prime}\right)-16 \quad 2 \quad 15 \text { sec } 0.01724 \\
& \mathrm{H}^{\prime}=\begin{array}{llll}
45 & 49 & 48 & \text { sec } 0.15690
\end{array} \\
& \frac{1}{2} d 6^{\circ} 20^{\prime} 36^{\prime \prime} \\
& \begin{array}{llll}
\mathrm{A}^{\prime} & 20 & 18 & 21
\end{array} \\
& \frac{1}{2} d+\mathrm{A}^{\prime} \quad \overline{56 \quad 38} 57 \quad \text { sec } 0.25982 \\
& \begin{array}{llll}
h^{\prime} & 24 & 13 & 51
\end{array} \\
& \sec 0.04005 \\
& \mathrm{H}^{\prime}+\frac{1}{2} d-\mathrm{A}^{\prime}=\overline{61 \quad 52} 3 \quad \cos 9 \cdot 67349 \\
& \rho-\pi=38 \quad 6 \quad \log 3.35908 \\
& \begin{array}{ccc}
h^{\prime}+\frac{1}{2} d+\mathrm{A}^{\prime}= & =\overline{805248} & \cos 9 \cdot 20004 \\
\zeta^{\prime}-\pi^{\prime} & 2^{\prime} 5^{\prime \prime .5} & \log 2 \cdot 09864
\end{array} \\
& \mathrm{M}=+2649.5 \log \overline{3.20671} \\
& \mathbf{s}=
\end{aligned}
$$

$$
\xi=\frac{72}{7231} \quad \begin{array}{ll}
39 \cdot 7 & 12 \cdot 5 \\
22 \cdot 3 &
\end{array}
$$

3rd corr.

$$
\begin{array}{lrr}
\theta= & 7231 & 25.9 \\
r= & 15 & 18.7 \\
r^{\prime}= & 16 & 4 \cdot 6
\end{array}
$$

True dist. of centres $\overline{73 \quad 249 \cdot 2}$

$73 \quad \begin{aligned} & 2 \\ & 39 \cdot 0\end{aligned} 0^{\circ} 9^{\prime} 49^{\prime \prime} \cdot 8 \ldots$ pr. $\log .1 \cdot 2627$

From Nautical Almanac pr. $\log .0 .3111$

Mean time at Greenwich $2120 \quad 7 \ldots \ldots$ pr. $\log . \overline{0.9516}$ Mean time at ship ...... $22 \quad 0 \quad 0$

Longitude in time ..... $\overline{0 \mathbf{3 9 5 3}}$ East. 
The third correction is to rectify the error committed in assuming one side of a spherical triangle equal to the adjacent segment of its base cut off by a perpendicular from the vertex of the opposite angle, which error will diminish with the angle contained between the above side and the base.

Suppose $a$ and $c$ to be two sides of a triangle, and $b$ and $d$ their adjacent segments, and $\mu=a-b$, then is $\tan \frac{1}{2} \mu$ $=\frac{\tan \frac{1}{2}(c-d) \cdot \tan \frac{1}{2}(c+d)}{\tan \left(b+\frac{1}{2} \mu\right)}$, whence $\mu$ may be found by approximations, supposing it in a first one $=0$. But $\tan \frac{1}{2}(c-d) \cdot \tan \frac{1}{2}(c+d)=\tan ^{2} \frac{1}{2} \lambda$, if we denote by $\lambda$ the perpendicular. And tang $\frac{1}{2} \mu=\frac{\operatorname{tang}^{2} \frac{1}{2} \lambda}{\operatorname{tang}\left(b+\frac{1}{2} \mu\right)^{\circ}}$.

Whence we find the following general expression for $\frac{1}{2} \mu$, which may be reduced accordingly as circumstances allow:

Suppose,

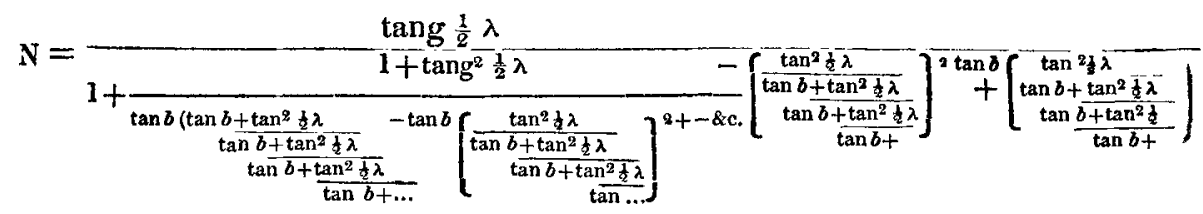

then is : tang $b$ tang $\frac{1}{2} \mu=\mathrm{N}-\mathrm{N}^{2}+\mathrm{N}^{3}-\mathrm{N}^{4}+\mathrm{N}^{5}-+-\ldots$ $\mu$ becomes, therefore, negative when $b>90$, and is $=0$ when $b=90^{\circ}$.

Walbeck, who proposed computing for the time of observation, reduced for the estimated longitude from the first meridian, the apparent distance as seen from the place of observation; and to derive, by a comparison of this computed distance with the observed one by means of the moon's apparent horary motion, the error of the estimated longitude, bas remarked already the necessity of computing the refraction for the points of contact when the altitudes are low, in the note to page 15 of his Dissertatio de Modo reducendi Distantias, Abo 1817: "Si rigorose calculaveris, refractio non pro Centro lunæ sed puncto limbi quo distantia capitur sumenda est. Inutile vero est, calculum talibus minutiis molestum reddere, quæ præterea, nisi sit luna vel sol horizonti proximus nullius sunt momenti. Ex hac etiam caussa minimæ altitudines evitari debent." But low altitudes are better than none, and cannot always be avoided.

Walbeck found from latitude, declination and horary angle, the altitudes, parallactic angle and the corrections of the altitudes, and thence the apparent declinations and right ascen- 
sions of both bodies, and computed thence, with true difference of right ascensions and true declinations, the true distance, and with the apparent difference of right ascensions and apparent declinations, the apparent distance, and the differences $\Delta^{\prime}-\Delta$ of these apparent and true distances for three successive equally distant periods $t_{1}, t_{2}, t_{3}$, and denoted by $\omega_{1}, \omega_{2}, \omega_{9}$, the remainders left by a subtraction of these differences $\Delta^{\prime}-\Delta$ from one another.

Suppose now $\omega_{1}=\mathbf{A}+\mathbf{B} t_{1}+\mathbf{C} t_{1}^{8}, \omega_{2}=\mathbf{A}+\mathbf{B} t_{2}+\mathbf{C} t_{2}{ }^{2}$, and $\omega_{3}=\mathbf{A}+\mathbf{B} t_{3}+\mathbf{C} t_{3}^{2}$, then is,

$$
\begin{aligned}
& \mathbf{C}=\frac{\omega_{1}\left(t_{3}-t_{2}\right)+\omega_{2}\left(t_{1}-t_{3}\right)+\omega_{3}\left(t_{2}-t_{1}\right)}{\left(t_{2}-t_{1}\right)\left(t_{3}-t_{1}\right)\left(t_{3}-t_{2}\right)} \\
& \mathbf{B}=\frac{\omega_{2}-\omega_{1}}{t_{2}-t_{1}}-\mathbf{C}\left(t_{2}+t_{1}\right) \text { and } \mathbf{A}=\omega_{1}-t_{1}\left(\mathbf{B}+t_{1} \mathbf{C}\right),
\end{aligned}
$$

whence any other $\omega=\mathbf{A}+\mathbf{B} t+\mathbf{C} t^{2}$ for any given $t$ may be found, provided $\mathrm{A}$ is assumed proportional to the given $t$; Then $\omega \pm$ sum of apparent semidiameters applied to the distance taken from the Naut. Almanac for the time reduced for longitude to the first meridian, gives the apparent distance of limbs, which by a comparison with the observed distance will show the error of the assumed longitude. This rather laborious proceeding may be simplified by taking also from the Nautical Almanac for the same reduced time, together with the other elements, the true distance of the centres, and finding by $\frac{\text { differ. } R \text { cosin declin. }}{\text { sine distance }}$, the sines of the angles of position for the sun, as well as for the moon; then a subtraction of the parallactic angles from the angles of position will give the above-mentioned angles $S$ and $M$, whence will be found, $\Delta^{\prime}-\Delta=\left(\pi^{\prime}-\rho^{\prime}\right) \cos \mathrm{M}-(\rho-\pi) \cos \mathrm{S}+$ third correction, where $S$ and $M$ are considered acute; any doubts whether the angles of position are obtuse or acute, are easily decided, and the reduction of the refraction to the points of contact is accomplished in the same manner as before. This method offers advantages when by a series of observations the longitude of a place on shore is to be determined. At sea it would be unwise to neglect the opportunity of observing the altitudes above the visible horizon, considering that the latitude entering into the calculation of the altitudes rests upon no firmer base than the contemporaneously observed altitudes, and requires moreover a very unsafe reduction by dead-reckoning to the time and place of lunar observation, not to mention 
that the error of the estimated longitude affects the elements entering into the computed altitudes taken from the Nautical Ephemeris, of which the observed altitudes are independent. Immediately before or after new moons the faint image of the moon when she is high may be difficult to bring down to the horizon, and occupy such a position in respect of it, that neither upper nor lower limb can be correctly observed. The computed altitude of a fixed star is also more to be depended on than its observed one ; in these cases it is better to compute, particularly the high altitudes, with the reduced geocentric latitude, as the refraction corresponds thereto, which, by rights, ought to have been taken from the tables for the angle of the ray of light with the normal or with its complement; the altitude above the sensible horizon then requires only a trifling correction.

When the lower object is a star, and the moon's altitude is not too small, the usual methods are sufficiently correct, provided allowance is made for barometer and thermometer.

Here follows a specimen of the table of the contraction of the vertical diameter on account of the refraction, which is calculated for the mean diameter of the sun, and for mean refraction.

\begin{tabular}{|c|c|c|c|c|c|c|c|c|}
\hline \multirow[b]{2}{*}{ Altitude. } & \multicolumn{2}{|c|}{ Correction for } & \multirow[b]{2}{*}{ Altitude. } & \multicolumn{2}{|c|}{ Correction for } & \multirow[b]{2}{*}{ Alttidude. } & \multicolumn{2}{|c|}{ Correction for } \\
\hline & $\begin{array}{l}\text { Lower } \\
\text { Limb. }\end{array}$ & $\begin{array}{l}\text { Upper } \\
\text { Limb. }\end{array}$ & & $\begin{array}{l}\text { Lower } \\
\text { Limb. }\end{array}$ & $\begin{array}{l}\text { Upper } \\
\text { Limb. }\end{array}$ & & $\begin{array}{l}\text { Lower } \\
\text { Limb. }\end{array}$ & $\begin{array}{l}\text { Upper } \\
\text { Limb. }\end{array}$ \\
\hline $10^{\circ} 0^{\prime}$ & $-8^{\prime \prime}$ & $-8^{\prime \prime}$ & $7^{\circ} 20^{\prime}$ & $-14^{\prime \prime}$ & $-15^{\prime \prime}$ & $4^{\circ} 50^{\prime \prime}$ & $-26^{\prime \prime}$ & $-28^{\prime \prime}$ \\
\hline 950 & 9 & 9 & 710 & ]4 & 16 & 445 & 26 & 29 \\
\hline 940 & 9 & 9 & & 15 & 16 & 440 & 27 & 29 \\
\hline 930 & 9 & 9 & 650 & 16 & 17 & 435 & 27 & 30 \\
\hline 920 & 9 & 10 & 640 & 16 & 18 & 430 & 28 & 31 \\
\hline 910 & 10 & 10 & 630 & 17 & 18 & $4 \stackrel{25}{2}$ & 28 & 32 \\
\hline 90 & 10 & 10 & 620 & 18 & 19 & 420 & 29 & 33 \\
\hline 850 & 10 & 11 & 610 & 18 & 20 & 415 & 30 & 34 \\
\hline 840 & 11 & 11 & 60 & 19 & 21 & 410 & 31 & 35 \\
\hline 830 & 11 & 11 & 550 & 20 & 22 & 45 & 32 & 36 \\
\hline $8 \mathfrak{2 0}$ & 11 & 12 & 540 & 21 & 23 & 40 & 33 & 37 \\
\hline 810 & 11 & 12 & 530 & 22 & 24 & 355 & 34 & 38 \\
\hline 80 & 12 & 13 & 520 & 23 & 25 & 350 & 36 & 40 \\
\hline 750 & 12 & 13 & 510 & 24 & 26 & 345 & 38 & 42 \\
\hline 740 & 13 & 14 & 50 & 24 & 27 & 340 & 40 & 44 \\
\hline 730 & 13 & 14 & 455 & 25 & 27 & 335 & 42 & 45 \\
\hline
\end{tabular}

